\title{
PEMODELAN BAWAH PERMUKAAN METODE PRE-STACK TIME MIGRATION (PSTM) ISOTROPY DAN METODE PSTM ANISOTROPY HIGH ORDER MOVEOUT (HOM)
}

\author{
Ahmad Luthfin $^{1 *}$, Adi Susilo", Teguh Suroso ${ }^{2}$ \\ ${ }^{1}$ Jurusan Fisika, Fakultas MIPA, Universitas Brawijaya Malang 65145 \\ ${ }^{2}$ Senior Geophysics UTC Pertamina, Jakarta Pusat, DKI Jakarta 10110 \\ *ahmadluthfin@gmail.com
}

\begin{abstract}
ABSTRAK
Struktur bawah permukaan memiliki perlapisan yang sangat komplek, sehingga memungkinkan penjalaran gelombang seismik memiliki kecepatan yang berbeda tergantung arah rambatnya. Hal inilah yang mendasari perlunya proses pengolahan data dengan melibatkan parameter anisotropi $(\eta)$. Umumnya data seismik memiliki nilai anisotropi dengan presentase tertentu, sehingga tidak semua data harus diproses dengan proses anisotropi. Ketepatan metode migrasi yang digunakan dapat menghasilkan gambar penampang struktur bawah permukaan dengan resolusi yang tinggi. Penelitian ini bertujuan untuk memodelkan struktur bawah permukaan dengan menggunakan metode PSTM isotopi (lapisan isotropi) sedangkan untuk lapisan anisotropi dimodelkan dengan metode PSTM anisotropi HOM. Hasil dari metode PSTM isotropi berupa citra, dimana lapisan pertama pada CMP 2073-CMP 2413 hasilnya jelek (beresolusi rendah), tetapi untuk lapisan kedua dan ketiga tampak bagus (beresolusi tinggi). Pada saat diproses dengan PSTM anisotropi, peneliti menggunakan nilai $(\eta)$ sekitar 0,25 pada lapisan pertama. Berdasarkan hasil PSTM anisotropi pada CMP 2073-CMP 2413 model lapisan pertama menghasilkan citra beresolusi lebih tinggi (lebih bagus), sedangkan model lapisan kedua dan ketiga tidak mengalami kenaikan resolusi yang signifikan. Hal ini karena rasio far offset dan kedalaman lapisan pertama besar menyebabkan lapisan pertama mengalami efek anisotropi, sedangkan lapisan kedua dan ketiga tidak mengalami efek anisotropi.
\end{abstract}

Kata Kunci: Model Sintetik; Parameter Anisotropi; PSTM Isotropi; PSTM Anisotropi HOM.

\begin{abstract}
Sub-surface structure has complex layer. It causes seismic wave propagation having different velocity depend on the propagation direction. Hence, it is needed to process the data using anisotropic parameter $(\eta)$. In general, seismic data has anisotropic value in certain percentage. However, not at all the data have to be processed using anisotropic parameter. The accuracy of the used migration method shall produce the section of sub-surface structure in high resolution. This research was aimed to modelling of sub-surface structure using PSTM isotropic method (isotropic layer) weather. The anisotropic layer modelling of subsurface was modelled by using PSTM anisotropy HOM method. It was obtained PSTM isotropy image in which the first layer of CMP 2073-CMP 2143 was presented low resolution image but the second and third layer presented high resolution. In PTSM anisotropy HOM process, It was used $\eta$-value 0.25 on the first layer. Based on the result of PSTM anisotropy in CMP 2073-CMP 2143 first layer models produced higher resolution image. In addition, the second and third layers had not the significant increasing resolution image. Due to the highness of the far offset and depth ratio, the anisotropic effect in the first layer was generated. On the other hand in the second and third layer were not found anisotropic effect.
\end{abstract}

Keywords: Synthetic Model; Anisotropic Parameters; PSTM Isotropy;PSTM Anisotropy HOM. 


\section{PENDAHULUAN}

Struktur bawah permukaan bumi yang kompleks dan mengandung banyak kekayaan alam menjadikan sangat penting untuk mengetahui struktur dan kandungan bawah permukaan bumi. Bahkan kajian tentang bumi sendiri memiliki banyak cabang keilmuan, salah satunya ilmu geofisika. Ilmu geofisika merupakan ilmu yang mempelajari struktur bawah permukaan bumi dengan menggunakan parameter dan besaran fisika, diantara metode fisika yang sering digunakan adalah metode seismik refleksi, seismik refraksi, geomagnetik, geolistrik dan sebagainya. Hasil dari pengukuran geofisika berupa parameter fisika yang harus diolah dan dimodelkan, agar dapat diketahui informasi bawah permukaan.

Struktur batuan bumi secara alami merupakan batuan anisotropi, dimana dari berbagai bentuk perlapisan anisotropi perlapisan Vertical Transverse Isotropy (VTI) memiliki bentuk perlapisan mirip bentuk perlapisan batuan sebenarnya. ${ }^{1}$ Alasan inilah yang menjadikan pemodelan pada penelitian kali ini menggunakan media VTI.

Tahapan pengolahan data seismik memiliki tahapan yang sangat banyak dan panjang sesuai kebutuhan dan kualitas data yang diolah. Salah satu tahapan penting dalam pengolahan data seismik ini adalah tahapan migrasi. Migrasi data seismik adalah suatu proses untuk memetakan suatu penampang dengan cara even-even seismik dikembalikan posisinya pada tempat dan waktu yang sesuai. Tujuan migrasi seismik untuk meningkatkan resolusi lateral dengan menghilangkan efek difraksi pada titik-titik diskontinuitas (patahan). ${ }^{2}$ Salah satu jenis migrasi adalah jenis PSTM isotropi, namun jenis migrasi ini berdasarkan penelitian sebelumnya dianggap memiliki sedikit kekurangan dalam memetakan data yang memiliki nilai parameter anisotropi. ${ }^{3}$ Berdasarkan hal tersebut sehingga perlu tahapan berikutnya yakni tahapan PSTM anisotropi.

Data seismik tidak dapat dikatakan sebagai data isotropi secara keseluruhan, begitu juga tidak dapat dikatakan sebagai data anisotropi secara keseluruhan, melainkan nilai anisotropi itu terdapat dalam presentasi tertentu saja. Salah satu faktor penyebab efek anisotropi ini oleh adanya ratio offset dengan kedalaman bagitu besar, sehingga dapat meningkatkan stabilitas dan resolusi inverse $(\eta)$, sekurang-kurangnya X/D>1,5 kali $(X=$ far offset, $D=$ kedalam lapisan) sudah dapat menyebabkan efek anisotropi ${ }^{4}$ sehingga membutuhkan nilai $\eta$ untuk proses moveout dan migrasinya. Efek anisotropi akan terlihat setelah dilakukan koreksi Normal Move Out (NMO), seperti pada gambar 1.

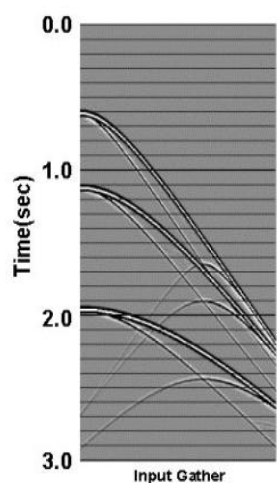

(a)

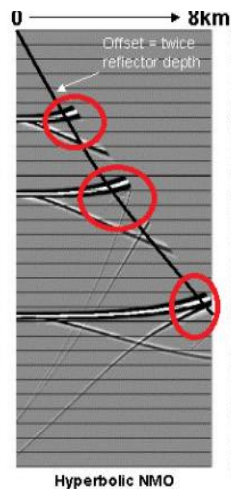

(b)

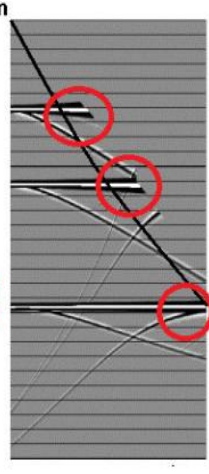

(c)

Gambar 1. CMP (Common Mid Point) gather (a) sebelum NMO, (b) setelah NMO isotropi (hyperbolic NMO), (c) setelah NMO anisotropi HOM. ${ }^{5}$ 
Data seismik mengandung nilai anisotropi dengan persentase tertentu, sehingga menjadikan hasil migrasi akan bagus jika tepat dalam pemilihan metode migrasinya.

\section{METODE PENELITIAN}

Penelitian kali ini peneliti menggunakan data sintetik dengan alasan metode migrasi PSTM anisotropi HOM merupakan pengembangan metode PSTM anisotropi, sehingga dengan menggunakan model data sintetik agar bebas noise. Ketepatan metode migrasi yang digunakan menjadi faktor utama keberhasilan pemodelannya.

Peneliti melakukan proses migrasi dua tahap, yakni PSTM isotropi dan PSTM anisotropi HOM. Migrasi data seismik pada prinsipnya merupakan suatu proses untuk memetakan suatu penampang menjadi penampang yang lain dimana even-even seismik dikembalikan posisinya pada tempat dan waktu yang tepat serta menghilangkan efek difraksi akibat patahan (berupa sesar, kubah garam, pembajian, dan kompleksitas struktur geologi lainnya), dengan demikian akan meningkatkan resolusi spasial pencitraan subsurface. Migrasi PSTM isotropi merupakan proses migrasi pada domain waktu dengan menganggap perambatan mediumnya homogen sama kesegala arah, travel time yang digunakan pada PSTM isotropi adalah seperti persamaan (1) di bawah ini.

$$
t_{x}=\sqrt{t_{o}^{2}+\frac{x^{2}}{v_{m i g}^{2}}}
$$

Berdasarkan persamaan (1) diatas $t_{x}$ adalah selang waktu untuk jarak x, $t_{o}$ adalah selang waktu pada zero offset, $x$ adalah jarak trace atau jarak antara sumber ledakan dan geophone, $v_{\text {mig }}$ adalah kecepatan gelombang untuk migrasi.

Metode PSTM anisotropi HOM adalah proses migrasi pada domain waktu yang melibatkan parameter anisotropi. Adapun travel time pada migrasi PSTM anisotropi HOM adalah seperti persamaan (2).

$$
t_{x}=\sqrt{t_{o}^{2}+\frac{x^{2}}{v_{\text {mig }}{ }^{2}}-\frac{2 \eta x^{4}}{v_{\text {mig }}{ }^{2}\left(t_{o}^{2} v_{\text {mig }}{ }^{2}+(1+2 \eta) x^{2}\right)}}
$$

Berdasarkan persamaan (2) $t_{x}$ adalah selang waktu untuk jarak x, $t_{o}$ adalah selang waktu pada zero offset, $x$ adalah jarak trace atau jarak antara sumber ledakan dan geophone, $v_{\text {mig }}$ adalah kecepatan gelombang untuk migrasi, $\eta$ adalah parameter anisotropi. Prinsip migrasi adalah mengembalikan letak reflektor keposisi sebenarnya mengikuti prinsip Huygens. ${ }^{6}$ Migrasi kirchoff dalam mengembalikan letak refleksi dengan melibatkan persamaan integral. ${ }^{7}$ Jika kedalaman lapisan jauh lebih kecil dari far offset maka akan terjadi efek anisotropi. ${ }^{8}$ Data yang mengalami efek anisotropi akan melibatkan beberapa parameter dalam perhitungannya diantaranya parameter $\eta .{ }^{9}$ Penelitian kali ini pemodelan lapisannya berupa lapisan datar, adapun migrasi pada lapisan datar dapat dilakukan seperti pada gambar 2. 


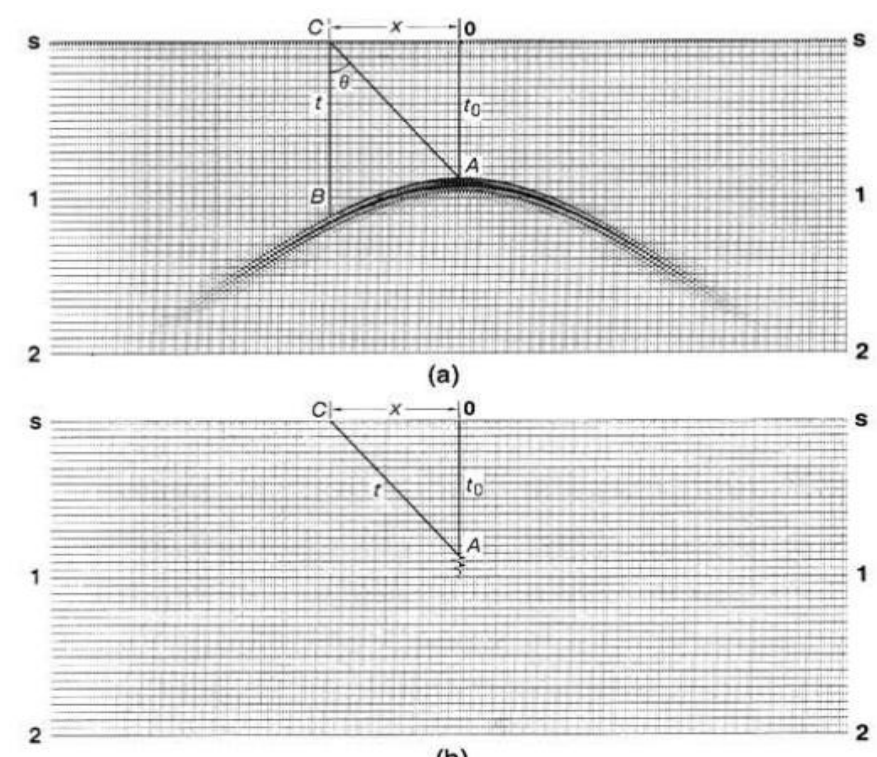

(b)

Gambar 2. Prinsip migrasi berdasarkan penjumlahan difraksi (a).Kurva difraksi (b). hasil Migrasi. $^{2}$

Bardasarkan gambar 2, solusi integral untuk persamaan Kirchoff adalah persamaan (3) sebagai berikut. ${ }^{1}$

$P_{\text {out }}(x, y, t=0)=\frac{1}{2 \pi} \int\left[\frac{\cos \theta}{r^{2}} P_{\text {in }}\left(x_{\text {in }}, z=0, t-r / v\right)+\frac{\cos \theta}{v r} \frac{\partial}{\partial t} P_{i n}\left(x_{i n}, z=0, t-r / v\right)\right] d x$.

Hasil migrasi berupa medan gelombang $P_{\text {out }}(x, y, t=0)$ pada subsurface $(x, z)$ dizero offset, medan gelombang masukan berupa $P_{i n}\left(x_{i n}, z=0, t\right)$, dimana pengukurannya pada permukaan (pada saat kedalaman $(\mathrm{z})=0$ ). Berdasarkan persamaan (3) di atas $r=\sqrt{\left(x_{i n}-x\right)^{2}+z^{2}}$ adalah jarak antara input dan output di $(x, z)$, hasil gambarnya dengan menggambarkan amplitudo di $\mathrm{t}_{\mathrm{o}}$ kedalam migrasi section.

Pada prinsipnya kurva difraksi yang dihasilkan tidak hanya satu melainkan puluhan sampai ratusan, sehingga hasil migrasi merupakan superposisi pada respon dititik puncak atau zero offset. $P_{i n}\left(x_{i n}, z=0, t\right)$ Adapun urutan kerja PSTM isotropi seperti gambar 3 .

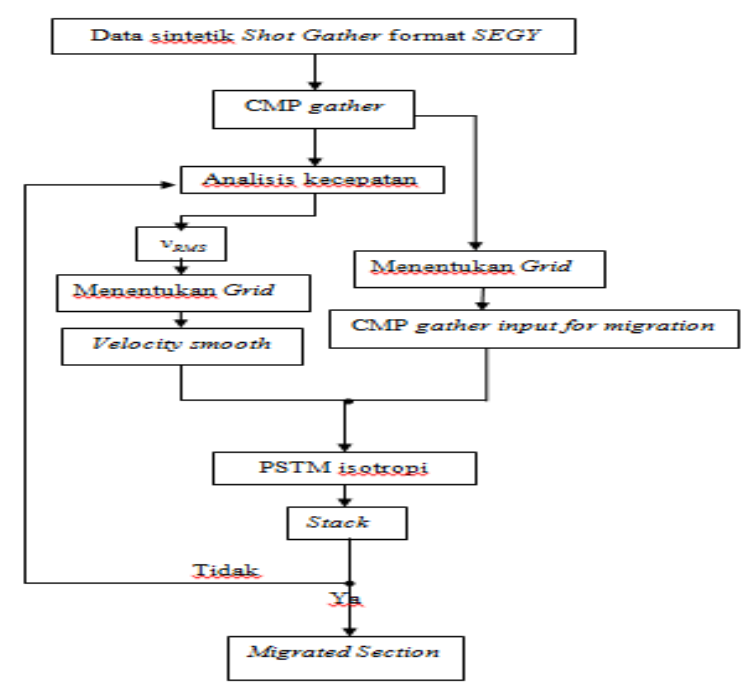

Gambar 3. Alur migrasi PSTM isotropi 
Berdasarkan gambar 3 menunjukkan proses migrasi isotropi memerlukan dua data input yakni model kecepatan smooth dan CMP gather. Apabila hasil migrasi masih tidak sesuai dengan yang diharapkan maka perlu dilakukan proses analisis kecepatan, yakni apakah estimasi nilai kecepatan yang digunakan sudah tepat atau tidak.

Model hasil migrasi PSTM isotropi tidak dapat memodelkan dengan baik pada lapisan yang memiliki nilai parameter anisotropi tertentu, padahal terdapat lapisan yang memiliki rasio far offset dengan kedalaman yang lebih dari 1,5 kali, lapisan ini menghasilkan efek anisotropi sehingga perlu dilakukan migrasi PSTM anisotropi HOM pada daerah yang memiliki nilai anisotropi tersebut. Alur tahap PSTM anisotropi HOM seperti gambar 4.

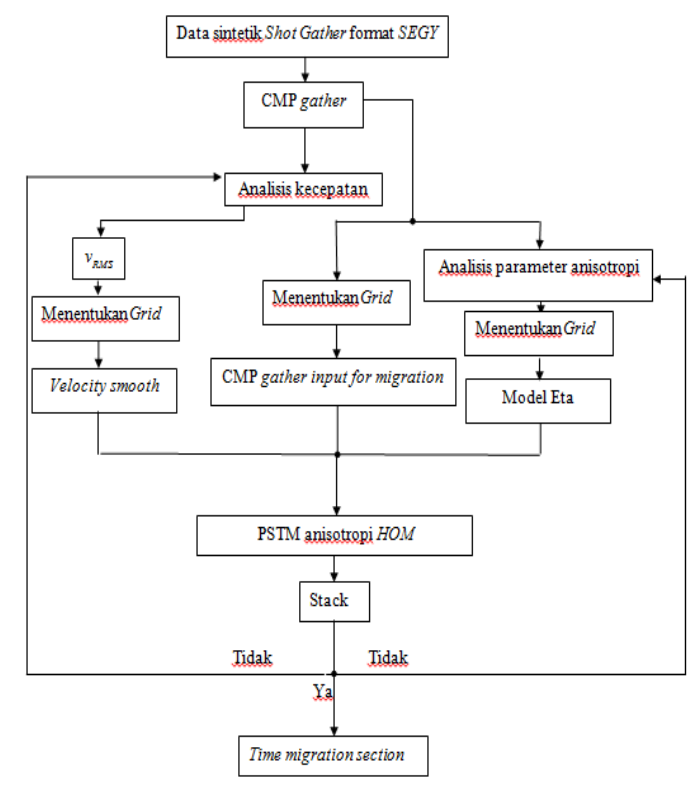

Gambar 4. Alur migrasi PSTM anisotropi HOM

Berdasarkan gambar 4 menunjukkan alur migrasi anisotropi HOM berbeda dengan PSTM isotropi. Perbedaannya adalah Metode PSTM anisotropi HOM memerlukan tiga inputan yakni, model kecepatan smooth, CMP gather dan model $\eta$ (parameter anisotropi)

\section{HASIL DAN PEMBAHASAN}

Data pada penelitian kali ini menggunakan data sintetik, untuk itu peneliti harus membuat pemodelan lapisan batuan dengan software tesseral. Pemodelan perlapisannya sebagai berikut.

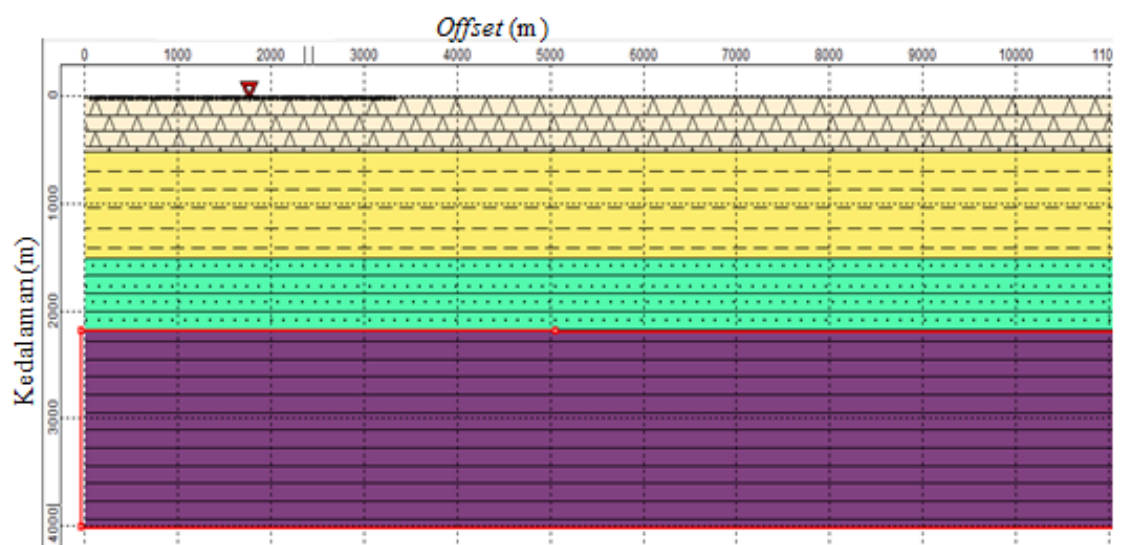

Gambar 5. Model perlapisan sintetik 
Berdasarkan gambar 5 sumbu vertikal menunjukkan kedalaman dan horisontal jarak (offset). Warna tersebut mewakili jenis batuan sedimen dengan nilai kecepatan tertentu, pada lapisan pertama adalah jenis batuan anhydrite dengan kecepatan $1500 \mathrm{~m} / \mathrm{s}$, lapisan kedua adalah jenis batuan clay dengan kecepatan $1800 \mathrm{~m} / \mathrm{s}$, lapisan ketiga adalah jenis batuan aleurolite dengan kecepatan $2400 \mathrm{~m} / \mathrm{s}$, sedangkan lapisan keempat atau terakhir adalah lapisan batuan argillite dengan kecepatan $3000 \mathrm{~m} / \mathrm{s}$. Adapun desain akuisisinya adalah sebagai berikut.

$\begin{array}{ll}\text { Sumber tenaga } & : \text { Gelombang elastic } \\ \text { Bentangan } & : \pm 9000 \mathrm{~m} \\ \text { Shot Interval } & : 50 \mathrm{~m} \\ \text { Receiver Interval } & : 25 \mathrm{~m} \\ \text { Banyaknya trace } & : 144 \\ \text { Number of Shot } & : 100 \\ \text { Near Offset } & : 12,5 \mathrm{~m} \\ \text { Far Offset } & : 1787,5 \mathrm{~m} \\ \text { Model Bentangan } & : \text { Split Spread simetri }\end{array}$

Hasil penembakan model sintetik diatas berupa shot gaher, kemudian dilakukan CMP sorting, menghasilkan CMP gather. Analisis parameter anistropi pada CMP gather melibatkan proses moveout yang ditunjukkan pada gambar 6.

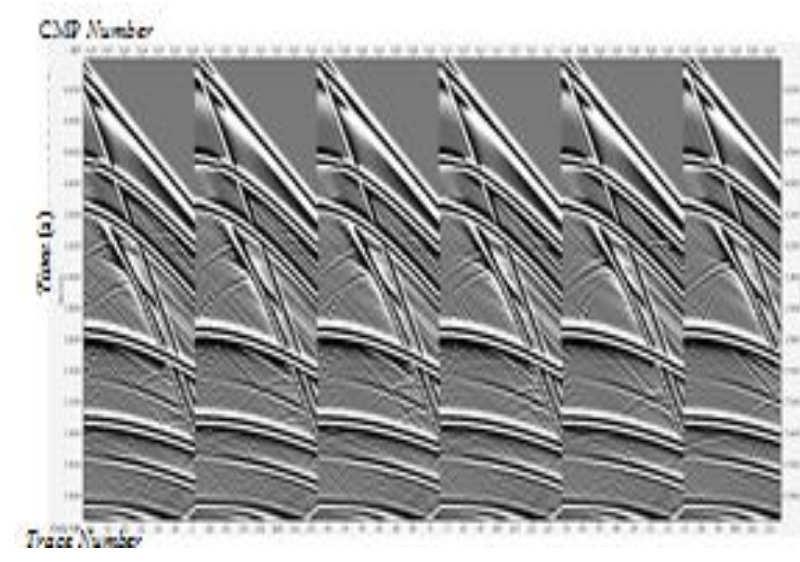

(a)

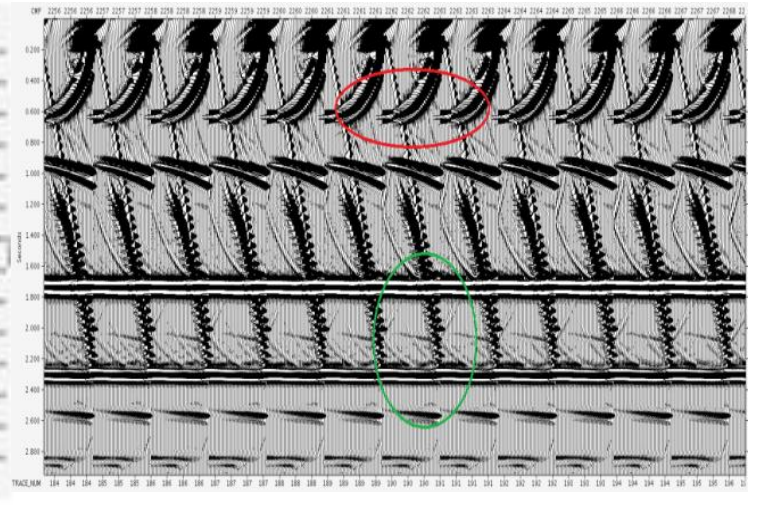

(b)



(c)

Gambar 6. Data sintetik (a). CMP gather (b). CMP gather yang di moveout dengan moveout hyperbolic (c). CMP gather yang di moveout dengan HOM $\eta=0,25$. 
Berdasarkan gambar 6(b) hasil moveout menunjukkan lapisan pertama (pada lingkaran merah) mengalami efek anisotropi hal ini dikarenakan besarnya kedalaman lapisan pertama hanya $500 \mathrm{~m}$, jauh lebih kecil jika dibandingkan dengan besarnya far offset 1875,5 m. Lapisan kedua dan ketiga (lingkaran hijau) hanya mengalami efek isotropi. Berdasarkan gambar 6(c) lapisan pertama pertama (pada lingkaran merah) akan termoveout dengan bagus ketika memasukkan nilai $\eta=0,25$. Hasil migrasi isotropi, pada metode migrasi PSTM isotropi ini peneliti tidak melibatkan nilai $\eta$, menghasilkan model seperti gambar 7 .

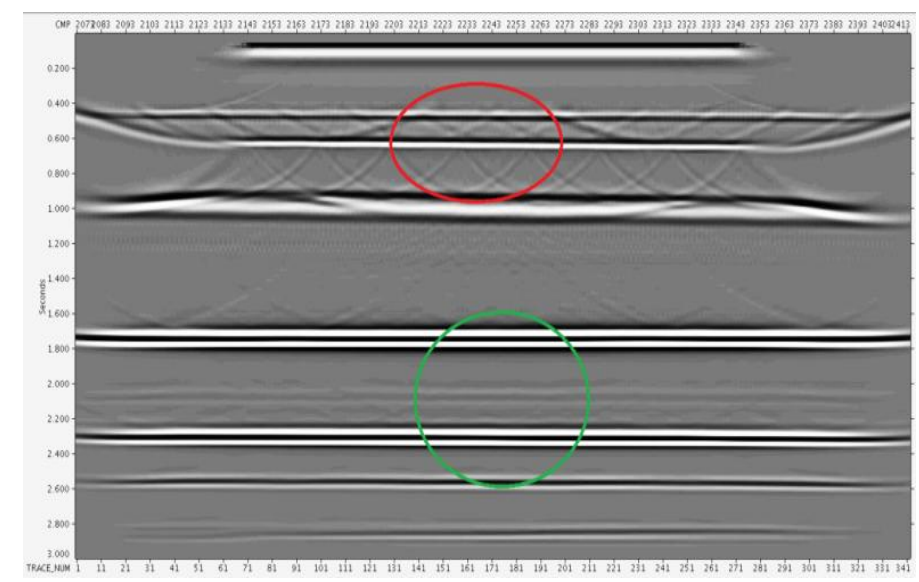

Gambar 7. Hasil migrasi PSTM isotropi

Berdasarkan gambar 7 lapisan pertama (lingkaran merah) mengalami resolusi yang sangat rendah sehingga tidak terlihat bentuk perlapisannya, sedangkan pada lapisan kedua dan ketiga seperti pada lingkaran hijau sudah terlihat bagus bentuk perlapisannya. Hal inilah yang menjadi alasan perlunya dilakukan migrasi PSTM anisotropi tepatnya pada lapisan pertama. Hasil migrasi PSTM anisotropi HOM dengan $\eta=0,25$ pada lapisan pertama seperti gambar 8 .

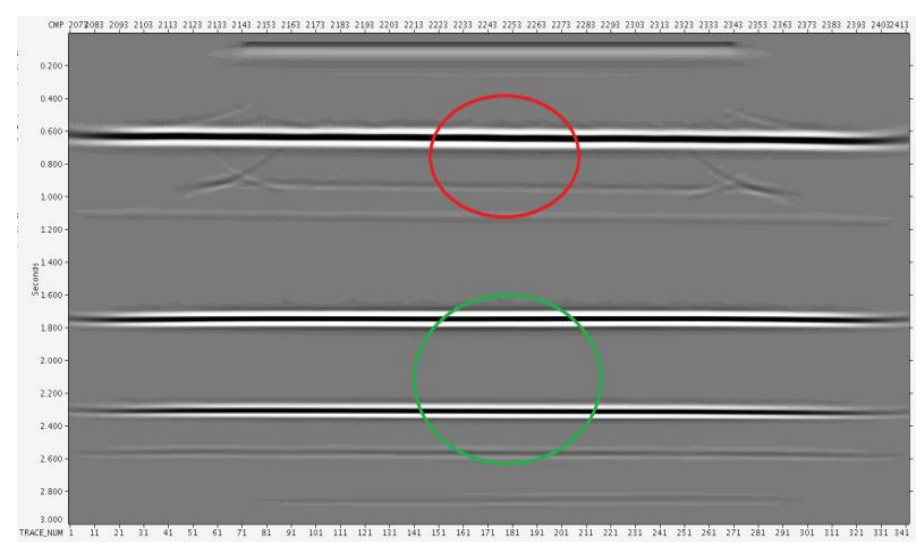

Gambar 8. Hasil migrasi PSTM anisotropi HOM

Berdasarkan gambar 8 menunjukkan pada lapisan pertama (lingkaran merah) hasil migrasi PSTM anisotropi HOM dengan $\eta=0,25$ memiliki resolusi tinggi dan jelas bentuk perlapisannya. Bentuk perlapisan pada lapisan pertama hasil migrasi PSTM anisotropi HOM dengan $\eta=0,25$ terlihat lebih bagus dari pada hasil PSTM isotropi, sedangkan pada lapisan ke-2 dan ke-3 pada lingkaran hijau, cukup hanya dengan migrasi isotropi. Hal ini karena lapisan ke-1 mengalami efek anisotropi sedangkan lapisan ke-2 dan ke-3 hanya mengalami efek isotropi. 


\section{KESIMPULAN}

Berdasarkan hasil penelitian kali ini didapatkan beberapa kesimpulan, diantaranya sebagai berikut:

1. Lapisan pertama dengan kedalaman $500 \mathrm{~m}$, memiliki rasio antara far offset dengan kedalaman lebih dari 3, sehingga lapisan pertama mengalami efek anisotropi. Berdasarkan hasil analisis, lapisan pertama mengandung nilai parameter anisotropi $\eta=0,25$ (mengalami efek anisotropi sebesar 25\%). Lapisan kedua dengan kedalaman $1500 \mathrm{~m}$ dan lapisan ketiga dengan kedalaman $2100 \mathrm{~m}$, masing-masing memiliki rasio far offset dengan kedalaman begitu kecil yakni 1,19 dan 0,85. Hal tersebut menyebabkan lapisan kedua dan ketiga tidak mengalami efek anisotropi.

2. Hasil citra metode PSTM isotropi data sintetik CMP 2073-CMP 2143 pada lapisan pertama memiliki resolusi yang sangat rendah, sedangkan lapisan kedua dan ketiga hasilnya sudah bagus (beresolusi tinggi) hanya dengan migrasi PSTM isotropi.

3. Hasil citra metode PSTM anisotropi HOM dengan nilai $\eta=0,25$ pada data sintetik CMP 2073-CMP 2143 beresolusi tinggi, dimana letak dan bentuk perlapisan pertama sesuai dengan bentuk perlapisan sebenarnya. Hal ini berbeda dengan hasil PSTM isotropi, sedangkan untuk lapisan kedua dan ketiga tidak dilakukan proses PSTM anosotropi HOM, karena dianggap sudah baik dengan hasil PSTM isotropi.

\section{UCAPAN TERIMA KASIH}

Penulisan menyampaikan ucapan terima kasih kepada Bapak Adi Susilo, Ph.D, selaku ketua komisi pembimbing dan Bapak Teguh Suroso, S.Si, M.Si (Senior geophysics UTC Pertamina) atas bimbingan, masukan, arahan dan motivasi kepada penulis selama penelitian.

\section{DAFTAR PUSTAKA}

1. Pedersen, Ø., B. Ursin, and A. Stovas. Wide-angle phase-slowness approximations in VTI media. GEOPHYSICS. 2007;72: S177-S185.

2. Yilmaz, O. Seismic data processing. Oklahoma: Society of Exploration Geophysicists; 1987.

3. Aziz, Panji, Maryanto, Sukir dan Nuruddin, Hasan. Pre-stack depth migration (PSDM) anisotropi VTI untuk pencitraan struktur bawah permukaan. Physics Student Journal. 2013;1(1):104-107

4. Alkhalifah, Tariq. Velocity analysis using nonhyperbolic moveout in transversely isotropic media. GEOPHYSICS.1997 November; 62(6):1839-1854

5. Tsvankin, I., and Thomsen, L. Nonhyperbolic reflection moveout in anisotropic media. GEOPHYSICS. 1994;59:1290-1304.

6. Sukmana, Andri, Kamalulloh, Ardi, Nanang D. Migrasi finite difference dan kirchoff pada data seismik refleksi 2D. FIBUSI (JoF). 2014 April;2(1):1-9

7. Gazdag, I dan Sguazzero, P. Migration of seismic data. Proceedings Of The IEEE. 1984 Oktober; 72(10):1302-1315

8. Fomel, S dan Grecka,V. Nonhyperbolic reflection moveout of p-wave: an overview and comparison of reasons. Center for Wave Phenomena (CWP). 2001 September; 372:1-23 
9. Thomsen, L. Weak elastic anisotropy. GEOPHYSICS .1986 Oktober; 51(10): 1954-1966 